\title{
Determination of Inorganic Arsenic as Arsenite in Water Samples by a Paper-Based Microfluidic Sensor System
}

\author{
Mason Bonacci, M. Inês G. S. Almeida, Spas D. Kolev \\ School of Chemistry, The University of Melbourne, Melbourne, Victoria 3010, Australia \\ s.kolev@unimelb.edu.au
}

\begin{abstract}
Sensing using disposable microfluidic paper-based analytical devices ( $\mu$ PADs) meets the increasing needs of rapid, accurate and low-cost monitoring and analysis for environmental protection and healthcare. $\mu$ PADs utilize the capabilities of cellulose fibres in paper to transport liquids by capillary force. This paper describes the development of a $\mu P A D$ for the determination of inorganic arsenic in aqueous samples as arsenite (As(III)). This is the first $\mu \mathrm{PAD}$ implementing a hydride generation approach on a paper-based platform for inorganic As determination. Arsine generated by the reaction of As(III) with sodium borohydride diffuses across a hydrophobic porous PTFE (Teflon) tape into the detection zone of the paper-based sensing system where it is oxidized by $\mathrm{Au}(\mathrm{III})$. The $\mathrm{Au}$ nanoparticles produced as a result of this reaction change the colour of the detection zone which can be related to the concentration of $\mathrm{As}(\mathrm{III})$ being reduced to arsine. Under optimal conditions the $\mu \mathrm{PAD}$

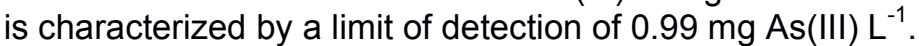

Key words: microfluidic paper-based analytical devices ( $\mu$ PADs), inorganic arsenic determination, hydride generation, water analysis.

\section{Introduction}

Arsenic pollution is of considerable environmental and health concern due to its ubiquitous nature. The toxicity of arsenic compounds depends significantly on their chemical form. Inorganic arsenic species are believed to be considerably more toxic than organoarsenicals [1]. The dominant inorganic arsenic species are arsenite $(\mathrm{As}(\mathrm{III}))$ and arsenate $(\mathrm{As}(\mathrm{V}))$, with the former being considerably more toxic than the latter [2]. The determination of inorganic arsenic has been successfully conducted in flow analysis systems utilizing a hydride generation approach where inorganic As has been reduced to arsine (e.g., [3-5]). Arsenite can be reduced more efficiently to arsine than arsenate and therefore in a number of studies the combined concentration of $A s(I I I)$ and $A s(V)$ has been determined after off-line reduction of $A s(V)$ to $A s(I I I)$ (e.g., [5]).

This paper described the first $\mu P A D$ for the determination of $\mathrm{As}(\mathrm{III})$ using a hydride generation approach combined with gasdiffusion separation of arsine from the sample matrix prior to its optical detection involving its oxidation by $\mathrm{Au}(\mathrm{III})$.

\section{Fabrication of the $\mu$ PAD}

The proposed $\mu$ PAD was credit card size (78 $\mathrm{mm} \times 58 \mathrm{~mm}$ ) and contained fifteen sensors, each consisting of 3 circular hydrophilic zones (Figure 1): (1) a sample zone (Zone 1), impregnated with $12 \mu \mathrm{L}$ of $0.8 \mathrm{M}$ hydrochloric acid solution; (2) a reagent zone (Zone 2) impregnated with $12 \mu \mathrm{L}$ alkaline sodium borohydride solution (1\% (w/v) $\mathrm{NaBH}_{4}$ and $0.1 \%(\mathrm{w} / \mathrm{v}) \mathrm{NaOH})$; and (3) a detection zone (Zone 3) impregnated with $1.5 \mu \mathrm{L}$ of $5 \mathrm{mM}$ $\mathrm{HAuCl}_{4}$ solution. Zone 2 and Zone 3 were separated by a PTFE hydrophobic microporous membrane. The $\mu$ PAD was oven-dried for $5 \mathrm{~min}$ at $40{ }^{\circ} \mathrm{C}$ and laminated for maintaining the alignment of the circular zones of each of its sensors and prevent the evaporation of the sample and $\mathrm{HAuCl}_{4}$ solution during the detection process. A Japanese screw punch was used to punch a sample insertion hole of 2 $\mathrm{mm}$ in diameter in the plastic cover over the centre of each sample zone (Zone 1) and Milli$Q$ water insertion hole at the end of the transport channel of each detection zone (Zone 3) (Figure 1). 


\section{Analytical procedure}

Prior to sample introduction, $1.5 \mu \mathrm{L}$ of Milli- $\mathrm{Q}$ water were deposited into the detection zone of each one of the 15 sensors of the $\mu P A D$ through the corresponding insertion hole. The analytical procedure was conducted at room temperature and involved the deposition of $12 \mu \mathrm{L}$ of sample or standard solutions into the individual sample insertion holes of the laminated $\mu P A D$, which were subsequently covered with a masking tape to prevent sample evaporation or loss of arsine gas. Arsine, produced in the sample and reagent zones, diffused across the PTFE (Teflon) tape and reduced $\mathrm{Au}(\mathrm{III})$ to $\mathrm{Au}$ nanoparticles thus changing the colour of the detection zones. These zones were scanned after a predetermined period of detection time using a conventional flatbed scanner.

Scanned images of the $\mu P A D$ were stored in JPEG format (1200 dpi). The mean intensity of the green colour of the center of detection zones was measured using ImageJ software (National Institute of Health USA, http://imagej.nih.gov./ij) and was subsequently converted to absorbance (eq. (1)) by the method of Birch and Stickle [6].

$A=-\log \left(1 / I_{0}\right)(1)$

where $I$ is the mean green colour intensity corresponding to the sample or standard and $I_{0}$ is the mean green colour intensity of the blank.
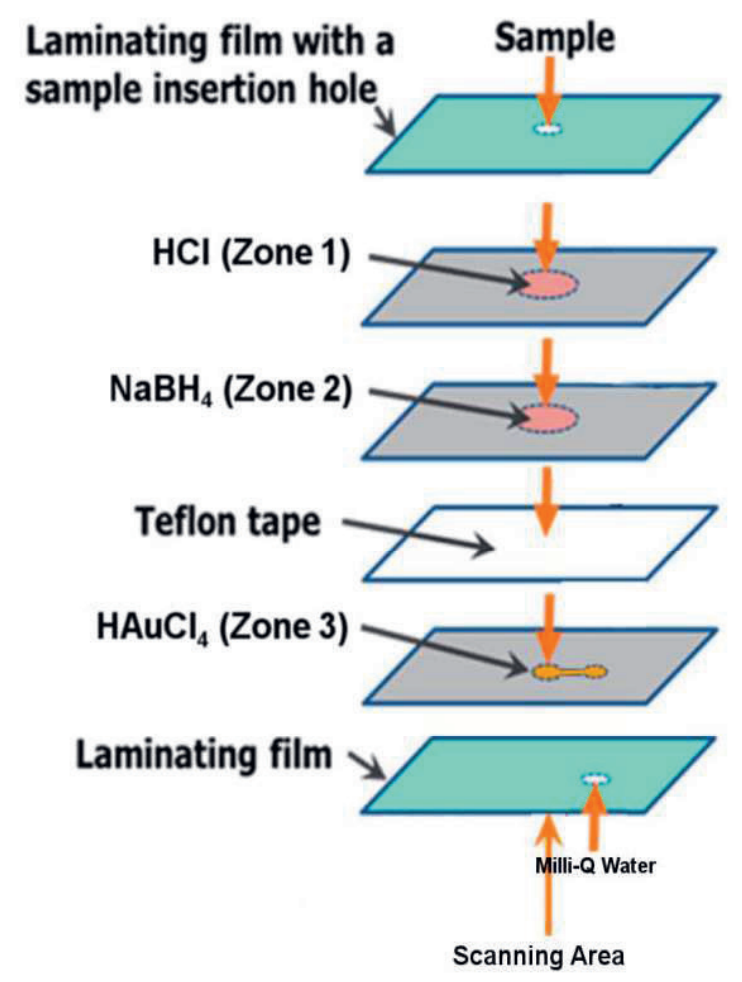

Fig. 1. Schematic representation of the hydride generation $\mu P A D$ for inorganic As determination.

\section{Optimization of the $\mu$ PAD}

Table 1 lists the parameters which were optimized together with the optimization ranges and the corresponding optimal values.

Tab. 1: Optimization results.

\begin{tabular}{|l|c|c|}
\hline Parameter & Range & $\begin{array}{c}\text { Optimal } \\
\text { value }\end{array}$ \\
\hline $\mathrm{HCl}($ Zone 1) $[\mathrm{M}]$ & $0.05-2.0$ & 0.80 \\
\hline $\mathrm{NaBH}_{4}$ (Zone 2) $[\%(\mathrm{w} / \mathrm{v})]$ & $0-1.6$ & 1.0 \\
\hline $\mathrm{HAuCl}_{4}$ (Zone 3) $[\mathrm{mM}]$ & $1-15$ & 5 \\
\hline Sample volume $[\mu \mathrm{L}]$ & $6-18$ & 12 \\
\hline Detection time $[\mathrm{min}]$ & $1-30$ & 5 \\
\hline
\end{tabular}

Analytical figures of merit of the $\mu$ PAD

Table 2 lists the analytical figures of merit.

Tab. 2: Analytical figures of merit.

\begin{tabular}{|l|l|}
\hline Parameter & Value \\
\hline Limit of detection for As(III) $\left[\mathrm{mg} \mathrm{L}^{-1}\right]$ & 0.99 \\
\hline Interdevice repeatbility (3 $\mu$ PADs) [\%] & 4.32 \\
\hline Intradevice repeatability (3 $\mu$ PADs) [\%] & 5.07 \\
\hline
\end{tabular}

\section{References}

[1] V. K. Sharma, M. Sohn, Aquatic arsenic: Toxicity, Speciation, Transformations, and Remediation, Environ. Int. 35, 743-759 (2009); doi: 10.1016/j.envint.2009.01.005

[2] C. K. Jain, I. Ali, I. Arsenic Occurrence, Toxicity and Speciation Techniques. Wat. Res. 34, 43044312 (2000); doi: 10.1016/S00431354(00)00182-2

[3] C. Lomonte, M. Currell, R. J. S. Morrison, I. D. McKelvie, S. D. Kolev, Sensitive and Ultra-Fast Determination of Arsenic(III) by Gas-Diffusion Flow Injection Analysis with Chemiluminescence Detection. Anal. Chim. Acta 583, 72-77 (2007); doi: 10.1016/j.aca.2006.09.049

[4] S. Satienperakul, T. J. Cardwell, S. D. Kolev, C. E. Lenehan, N. W. Barnett, A Sensitive Procedure for the Rapid Determination of Arsenic(III) by Flow Injection Analysis and Chemiluminescence Detection. Anal. Chim. Acta 554, 25-30 (2005); doi: 10.1016/j.aca.2005.08.025

[5] T. Rupasinghe, T. J. Cardwell, M. D. Luque de Castro, R. W. Cattrall, S. D. Kolev, Pervaporation Flow Injection Determination of Arsenic Based on Hydride Generation and the Molybdenum Blue Reaction, Anal. Chim. Acta 445 (2001) 229-238; doi: 10.1016/S0003-2670(01)01256-9

[6] N. C. Birch, D. F. Stickle, Example of Use of a Desktop Scanner for Data Acquisition in a Colorimetric Assay, Clin. Chim. Acta 333, 95-96 (2003); doi:10.1016/s0009-8981 